\title{
Lobular Capillary Hemangioma of the Hypopharynx
}

\author{
Tae Hoon An, Seung Jin Park ${ }^{(D)}$, Min Jun Shin, and Yong Jin Song ${ }^{(i)}$ \\ Department of Otorhinolaryngology, Gangneung Asan Hospital, University of Ulsan College of Medicine, Gangneung, Korea
}

\author{
하인두의 소엽성 모세관 혈관종 \\ 안태훈 · 박승진 · 신민준 · 송용진 \\ 울산대학교 의과대학 강릉아산병원 이비인후과학교실
}

\author{
Received November 18, 2020 \\ Revised January 3, 2021 \\ Accepted January 13, 2021 \\ Address for correspondence \\ Yong Jin Song, MD, PhD \\ Department of Otorhinolaryngology, \\ Gangneung Asan Hospital, \\ University of Ulsan \\ College of Medicine, \\ 38 Bangdong-gil, Sacheon-myeon, \\ Gangneung 25440, Korea \\ Tel $+82-33-610-3309$ \\ Fax $+82-33-642-3189$ \\ E-mail yjsong.yjs@gmail.com
}

\begin{abstract}
Lobular capillary hemangioma (LCH) is a rapidly growing benign vascular neoplasm of unknown etiology. LCH usually occurs on the cutaneous and mucosal surfaces, such as gingiva, lips, fingers, and face. LCH was previously called 'pyogenic granuloma (PG),' because it was thought to be granulation of tissue occurring in reaction to an infectious etiology despite the fact that it demonstrates no infectious signs in histology or microbiology. Instead, its features seem more like angiomatous lesions rather than granulomatous lesions, so the term ' $\mathrm{LCH}$ ' has been used thereafter. Reports of LCH of hypopharynx have been rare. Here we report a 63-yearold male patient with LCH of hypopharynx with a review of related literature.
\end{abstract}

Korean J Otorhinolaryngol-Head Neck Surg 2022;65(1):41-44

Keywords Lobular capillary hemangioma; Pyogenic granuloma; Vascular neoplasms.

\section{Introduction}

Lobular capillary hemangioma (LCH) is a common nonneoplastic vascular lesion of the skin and mucosa. It is sessile or pedunculated smooth nodule characterized by a lobular arrangement of capillaries. Secondary ulceration, edema, hemorrhage, and inflammatory changes are common in this tumor. LCH may occur in patients of all ages and sexes but predominant in the second decade of life in young adult females. ${ }^{1)}$ Head and neck is the most common anatomical location including gingiva, lips, fingers, and face. There are few cases reported earlier in the literature of LCH in larynx and trachea. A 10-year retrospective analysis of 86 cases from Akamatsu, et al. ${ }^{2)}$ showed that the head and neck area were the most commonly affected sites, but most of the mucosal lesion $(92.3 \%)$ was limited to the oral cavity. and Giblin, et al. ${ }^{3)}$

This is an Open Access article distributed under the terms of the Creative Commons Attribution Non-Commercial License (https://creativecommons.org/licenses/by-nc/4.0) which permits unrestricted non-commercial use, distribution, and reproduction in any medium, provided the original work is properly cited. also reviewed 388 cases retrospectively for optimum treatment of $\mathrm{LCH}$, and there was a only mention about the location that intraoral and intranasal lesions were about $20 \%$ of head and neck LCH. Hypopharyngeal localization has been reported previously, and it was extremely rare. ${ }^{4)}$ We report a case of LCH of the hypopharynx, its findings on computed tomography $(\mathrm{CT})$ image, and pathological findings.

\section{Case}

A 63-year-old male visited our hospital with symptoms of a foreign body sensation in the throat and mild dysphagia for 10 days. Although he had been evaluated at other facility and a mass in throat was identified 3 months before, he did not concern about it because there was no symptom. He had a history of a spine surgery (and so endotracheal intubation) under general anesthesia six years ago. Transnasal fiberoptic laryngoscopy showed an exophytic pinkish, multilobulated mass in posterior pharyngeal wall near the left arytenoid and pyriform 
sinus (Fig. 1). We planned laryngeal microsurgery and recommended him to remove the lesion, but he denied the surgery.

After 2 months, symptoms aggravated, and mass size also increased on laryngoscopic examination. After all, the patient agreed to the surgery. Preoperative neck CT showed an $1.3 \times$

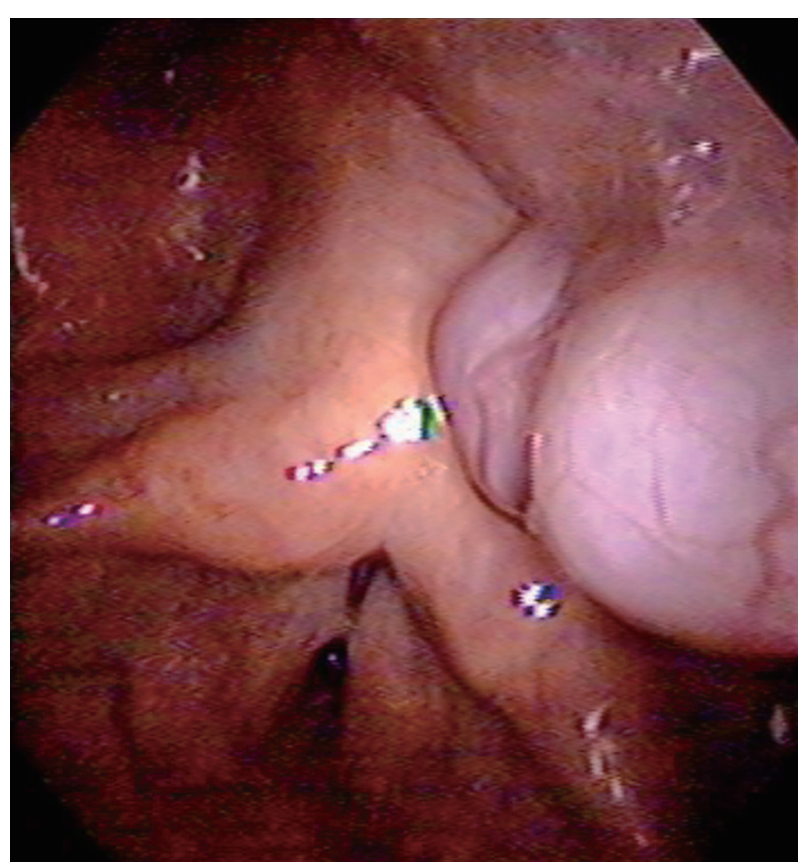

Fig. 1. Preoperative fiberoptic laryngoscopic view of the mass showing exophytic pinkish, multilobulated mass in posterior pharyngeal wall.

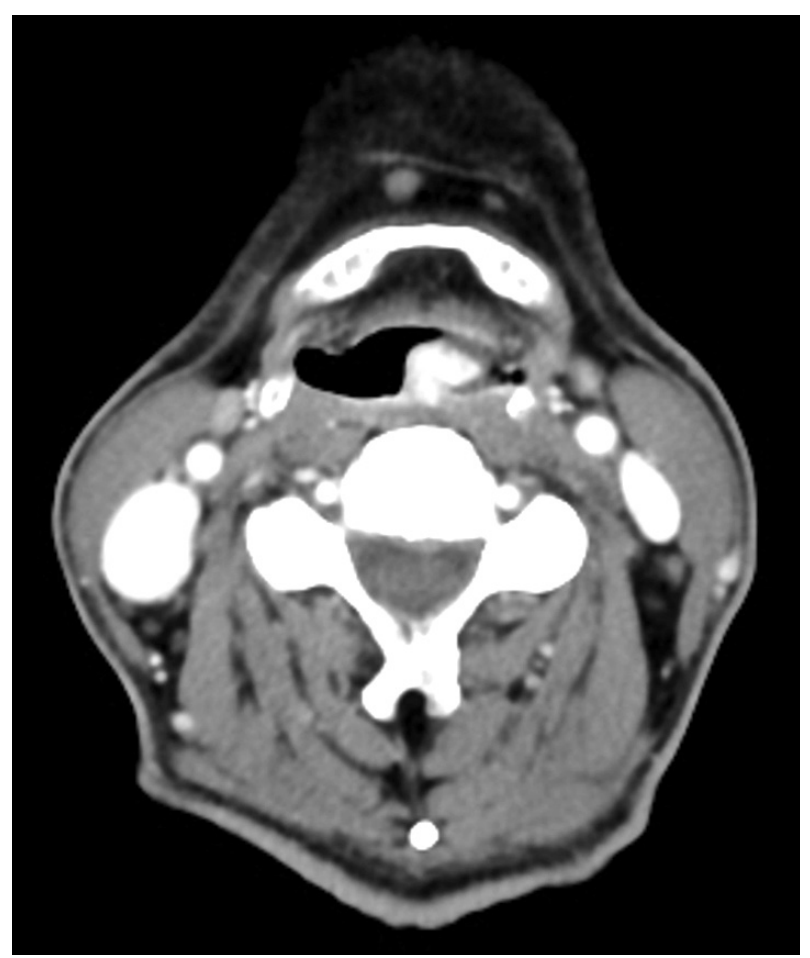

Fig. 2. An axial neck CT reveals a $1.3 \times 1 \mathrm{~cm}$ sized intensely enhancing, pedunculated mass from posterior pharyngeal wall.
$1 \mathrm{~cm}$ sized intensely enhancing, pedunculated mass from posterior pharyngeal wall on axial view (Fig. 2). CT images of the mass confirmed that there was no invasion into adjacent structures and complete resection could be done. So further imaging study (e.g., magnetic resonance imaging) was not performed. An operation was performed under general anesthesia. On the microscopic view of a $400 \mathrm{~mm}$ optical zoom lens, lobulated pinkish mass arose from posterior pharyngeal wall was torned and bled easily, but it was excised entirely using microscissors, and bleeding was controlled successfully with monopolar coagulator and bosmin balls without any complication (Fig. 3).

A histopathologic examination of a specimen revealed lobulated capillary proliferation in a fibromyxoid stroma (Fig. 4). It had partially ulcerated epithelium and exudate on the surface. It was diagnosed as a LCH. After the operation, he discharged without postop bleeding, dyspnea or any other complication. At tenth postoperative day, the lesion was nearly healed in fiberoptic laryngoscopic view at his first office visit (Fig. 5). Now he is doing well for one year without recurrence.

\section{Discussion}

The previous term 'pyogenic granuloma (PG)' was coined by Hartzell ${ }^{5)}$ in 1904 as 'granuloma pyogenicum.' The lesion was first thought to be granulation tissue in reaction to an infectious etiology. Mills, et al. ${ }^{6}$ ) used the term 'LCH' in 1980 to characterize the histopathological appearance of these lesions. They determined an essential components of the le-

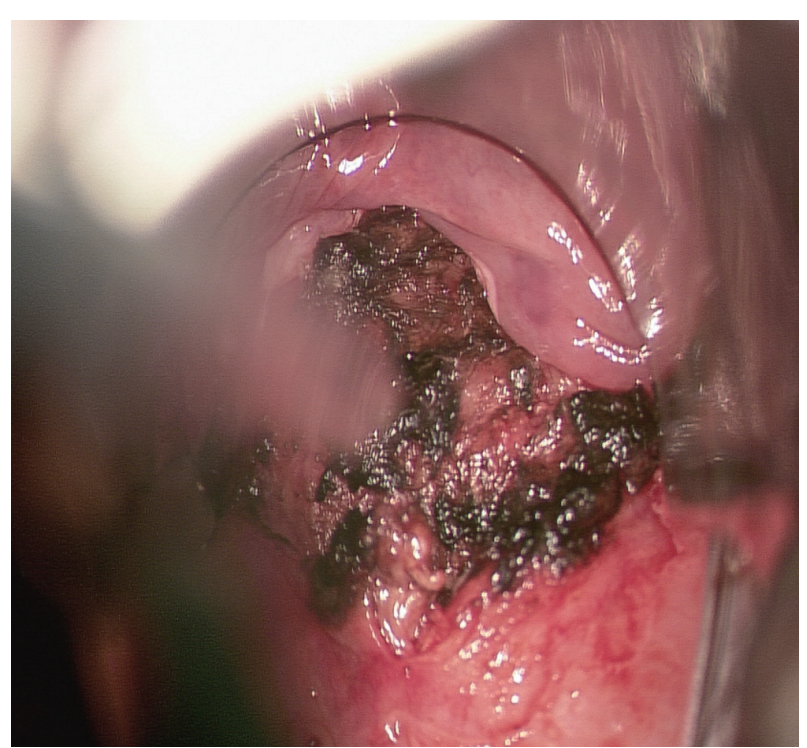

Fig. 3. The image of the posterior pharyngeal wall after surgical excision of the mass. 


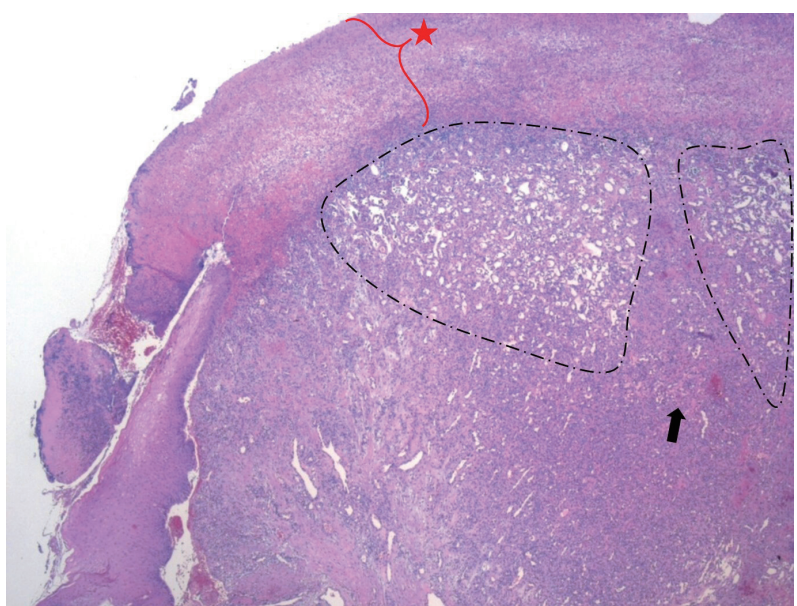

Fig. 4. Histopathologic image under light microscopy (hematoxylin and eosin, $\times 20$ ). There is a lobulated proliferation of capillarysized vessels (in dotted line) and lobules are separated by fibromyxoid septa (arrow). Ulceration with exudate $(\star)$ is observed on the surface.

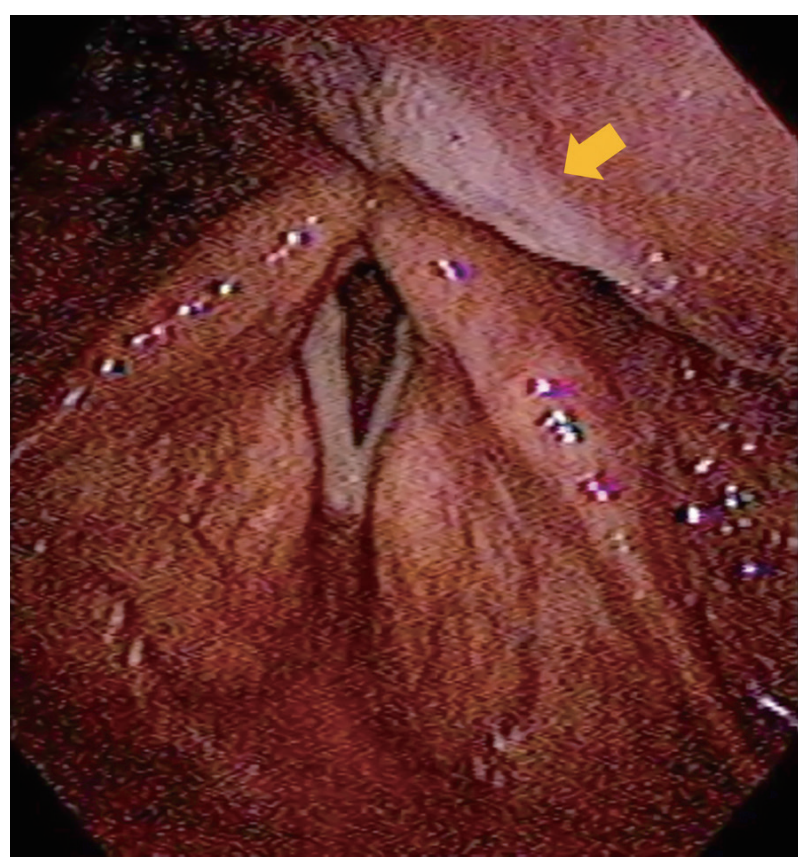

Fig. 5. Transnasal fiberoptic laryngoscopic findings of the posterior pharyngeal wall, which is nearly healed at tenth postoperative day (arrow).

sion are a circumscribed aggregation of capillaries arranged in one or more lobules, and inflammatory infiltration is slight. It is often covered by atrophic/hyperplastic epithelium which may be ulcerated at times, and is revealed fibrinous exudates. There is a lobulated proliferation of capillary-sized vessels, and myxoid or fibrous connective tissue septa separates the lobules. Immunohistochemistry is rarely carried out because the diagnosis can be easily made by light microscopy, but the additional test may be required for atypical and multiple le- sions. ${ }^{7)}$ In our case, there was also a typical pathologic feature of $\mathrm{LCH}$ in routine hematoxylin and eosin stain without the need of immunohistochemistry.

The precise mechanism for the development of $\mathrm{LCH}$ is unknown. Low-grade local irritation, trauma, sex hormonal influences, and drugs have all been postulated to play a role. ${ }^{8)}$

Garrett and Lee ${ }^{9)}$ reported a LCH as a result of blunt laryngeal trauma, which had tethered off the superior aspect of the vocal process. In this case, $\mathrm{LCH}$ was arised from the posterior pharyngeal wall. A posterior pharyngeal wall can be damaged by endotracheal intubation. This may play a role in the formation of LCH.

Most common site for occurrence of LCH is oral cavity, which can lead patients to have foreign body sense in mouth, burning sensation, halitosis, odynophagia mostly. ${ }^{2,8)}$ In the case of LCH in hypopharynx, dysphagia may occur likely due to the location more closer to upper esophageal sphincter, and also voice change and shortness of breath may occur likely due to the location more adjacent to the larynx, and hemoptysis may occur because ulcerated surface of mass could cause bleeding easily. ${ }^{4,7)}$

LCH reaches the maximum size typically within a few weeks and does not decrease over time. The size of mass varies from 0.5 to $4 \mathrm{~cm}$, with a mean diameter of $1.1 \mathrm{~cm}$. When LCH in oral cavity is small and asymptomatic, regular follow up and observation are advised. If the lesion is big or symptomatic, it should be removed. ${ }^{1)}$ In this case, the patient only have vague symptoms at first. It seems that the mass did not reach the maximum size that cause symptoms at that time. There are no sufficient cases of LCH in hypopharynx, so more cases need to be collected and further studies on the size of tumors that cause symptoms and the factors that increase size of tumor or risk of bleeding are necessary.

In LCH of the nasal cavity, contrast-enhanced CT is useful for not only in identifying the site of origin and assessing the extent but also in suggesting the nature. Lee, et al. ${ }^{10)}$ investigated CT features of an LCH lesion in nasal cavity which consists of an intensely enhancing mass and an iso- or hypoattenuating cap of variable thickness around. In this case, the utilization of CT in hypopharynx was confirmed as stated above. And the LCH of the hypopharynx was observed similar to nasal cavity lesion which is an enhancing mass with a hypo-attenuating cap.

When it was confirmed macroscopically or radiologically that mass in hypopharynx was highly vascularized, it would be better to perform excisional biopsy under intubated situa- 
tion with general anesthesia for protection against aspiration of bleeding rather than incisional biopsy with flexible laryngoscopy without protection of aspiration because LCH often has ulcerated surface and bleeds easily, and it may cause uncontrolled hemorrhage. If mass causes airway obstruction, tracheostomy before biopsy should be considered. ${ }^{11)}$

Mucosal LCH can be treated by surgical excision, laser excision using a $\mathrm{CO}_{2}$ laser, $\mathrm{Nd}: \mathrm{YAG}$ laser, and pulsed dye laser, cryosurgery, etc. In this case, the lesion was excised entirely by surgery without recurrence. Giblin, et al. ${ }^{3)}$ report excision and primary closure is the most effective method for eradicating PG with a recurrence rate of 3.6\%. However, the report contains the entire LCH of skin and mucosal lesions. Jafarzadeh, et al. ${ }^{1)}$ introduced many treatment options for oral cavity $\mathrm{LCH}$, but there was no comparative analysis of these treatments. In mucosal LCH arosen from a head and neck lesion, more samples and various therapeutic approaches need to be collected to compare appropriate treatment effects.

In conclusion, $\mathrm{LCH}$ of the hypopharynx is a rare disease. Clinical manifestations are foreign body sense, dysphagia, and dyspnea.

In our case, the patient visited initially with only vague symptom. But symptoms were gradually aggravated, and mass size also increased. An operation was performed, the diagnosis was established, and the symptom was relieved. Although LCH of the hypopharynx is very rare case, but differential diagnosis of the symptomatic hypopharyngeal mass lesion must include $\mathrm{LCH}$.

We report the very rare case of $\mathrm{LCH}$ of the hypopharynx and a review of the literature.

\section{Acknowledgments}

None.

\section{Author Contribution}

Conceptualization: Yong Jin Song. Data curation: Tae Hoon An, Seung Jin Park, Min Jun Shin. Supervision: Yong Jin Song. Writing - original draft: Tae Hoon An, Yong Jin Song. Writing - review \& editing: Tae Hoon An, Yong Jin Song.

\section{ORCIDs}

Yong Jin Song https://orcid.org/0000-0003-1451-6676

Seung Jin Park https://orcid.org/0000-0002-2057-1594

\section{REFERENCES}

1) Jafarzadeh H, Sanatkhani M, Mohtasham N. Oral pyogenic granuloma: A review. J Oral Sci 2006;48(4):167-75.

2) Akamatsu T, Hanai U, Kobayashi M, Miyasaka M. Pyogenic granuloma: A retrospective 10-year analysis of 82 cases. Tokai J Exp Clin Med 2015;40(3):110-4.

3) Giblin AV, Clover AJ, Athanassopoulos A, Budny PG. Pyogenic granuloma - the quest for optimum treatment: Audit of treatment of 408 cases. J Plast Reconstr Aesthet Surg 2007;60(9):1030-5.

4) Yakirevitch A, Fridman E, Bedrin L. Pyogenic granuloma arising from vallecula. Otolaryngol Head Neck Surg 2006;134(1):175-6.

5) Hartzell ME. Granuloma pyogenicum. J Cutan Dis 1904;22:520523.

6) Mills SE, Cooper PH, Fechner RE. Lobular capillary hemangioma: The underlying lesion of pyogenic granuloma. A study of 73 cases from the oral and nasal mucous membranes. Am J Surg Pathol 1980;4(5):470-9.

7) Patterson JW. Weedon's skin pathology. 4th ed. Virginia, USA: Elsevier;2015. p.1093.

8) Krishnapillai R, Punnoose K, Angadi PV, Koneru A. Oral pyogenic granuloma--a review of 215 cases in a South Indian Teaching Hospital, Karnataka, over a period of 20 years. Oral Maxillofac Surg 2012; 16(3):305-9.

9) Garrett MM, Lee WT. Obstructing pyogenic granuloma as a result of blunt laryngeal trauma. Otolaryngol Head Neck Surg 2007; 136(3):489-90.

10) Lee DG, Lee SK, Chang HW, Kim JY, Lee HJ, Lee SM, et al. CT features of lobular capillary hemangioma of the nasal cavity. AJNR Am J Neuroradiol 2010;31(4):749-54.

11) Amy FT, Enrique DG. Lobular capillary hemangioma in the posterior trachea: A rare cause of hemoptysis. Case Rep Pulmonol 2012;2012:592524. 